\title{
Book Review \\ Construction Item Pricing For More Profit and Less Risk
}

David Cattell, UCT Press, 2012, 150 pages includes CD Rom, ISBN 9781919895697. Price USD 34.95, ZAR 265.00

David Cattell has written the next evolution in construction pricing approaches and strategies. $\mathrm{He}$ builds upon previous research breakthroughs in this area while acknowledging those whose work is foundational. Cattell's exhaustive research has made this book an important one for researchers and practitioners to study. In my reading, it clarified some grey areas concerning theory and practice. I am sure it will do the same for others.

Construction pricing is the first opportunity for construction firms to improve a project's financial outcome. Improved profit and cash flow calculate to a greater return on investment. The idea of improving a project's cash flow through line item pricing generates controversy. However, contractors still practice it and have an interest in improved approaches.

The business of construction contracting is a risk filled venture. Cattell recognizes this in his work. He captures the basic premise that faces all construction organizations, "maximising profit while minimising risk." It is well explained and structured in the pricing model he proposes. I believe this book is a foundational text for those serious about knowing more effective approaches to line item pricing in the construction industry.

Investment Banks are challenged with the same problem. They rely on three sources of input to their decision making process. Firstly, "perfect information", that is, corroborated facts and data. Secondly, mathematical models which reflect all those factors and their relative effect on the business situation. Thirdly, computer software that calculates the model. In essence, a commercial decision-making system quantifies risk and prices it accordingly. Cattell's model achieves the same for contractors.

Cattell included a welcome extension. His book furnishes the source code for the program he wrote for implementing his model. His equation includes critical items such as timing, schedule confidence, rate of escalation, expected variations of counts and client's potential rejection of pricing.

The software provides a test of the new model. As a final exhibit in the CD-ROM included with the book, it lists optimal pricing for each of 503 items featured in the book's case study.

For the industry practitioner or academic, this is an evolutionary work that should be studied. It is a building block for anyone's knowledge of construction pricing. It is an improvement over previous works and has to be considered by the next evolutionary person.

Overall in today's competitive environment, a detailed computer-pricing model that is reflective of real world factors can quickly start a fact-based discussion The quicker that factbased discussion starts the better the quality of the "art" of final decision-making. This is what Cattell offers in his mathematical model and computer language. I believe it affords a competitive edge in producing less risk and more reward for contractors than previous approaches.

Matt Stevens

Senior Lecturer in Construction

The Faculty of Architecture, Building and Planning

The University of Melbourne 